\title{
The application of Analysis Hierarchy Process to Identification of Risk Factors in PFI of Construction of Small Towns
}

\author{
Rong Song \\ Shaanxi Institute of International Trade\& Commerce College, Xian Yang 710026, China \\ songrong2008@126.com
}

Keywords: Analysis Hierarchy Process, establishment of small towns, risk estimation, PFI.

\begin{abstract}
In order to extract the section that suffer from the highest risk in establishments of small town, In Analysis Hierarchy Process, the relevant elements are divided into objectives, guidelines, programs and other levels to qualitative analysis and quantitative analysis, and on this base, the final decision is made. In this paper, Analysis Hierarchy Process is introduced. And the risk estimation of four sections are taken as analysis data. As result shown, the project companies the principal components in all the section, therefore, more attention should be paid to the project company. And the result may be worth considering as making establishment plan.
\end{abstract}

\section{Introduction}

Small town's establishment, as an important part of urban infrastructure, is of great significance. PFI (Private Finance Initiative) that private finance initiative, is currently the widespread implementation, and is a new private capital investment in public construction project management. PFI model can overcome the traditional infrastructure of the high investment to a certain extent low efficiency and high consumption of resources and other defects, so it has highuse effective of private capital to solve the funding problem, and improves social capital efficiency to promote the development of the construction of small towns[1,2]. However, development cycle of PFI projects with large investment is long, involving the main complex, characterized by many unpredictable factors, so that there is a big uncertainty and risk throughout the cycle, and therefore a reasonable risk management is critical to the success of PFI operation, and risk identification and evaluation is the basis and premise of risk management. At present, the research on the financing model and risk management are many, but the small town construction financing model study is few, especially in terms of risk management focusing on how to understand the specific risk factors risk of uniform standards. In this paper, the risk of four sections participated in PFI projects are selected to quantitatively analyze by employing evaluation model based on AHP.

\section{Illustration of PFI}

PFI is an optimized BOT project financing, referring to the government department under the demand for infrastructure construction projects. The construction and operation of public infrastructure projects and concessions period (usually about 30 years) will be operated by the project intact. No debt is returned at the end of the government, and the private sector receive services from the government or party fees to recover the cost of the project financing.

\section{Calculation Process of Analysis Hierarchy Process}

According to the theory of analytic hierarchy process, the basic idea of AHP is to decompose complex decision problems, and get a number of underlying index, and then the lower indicators are decomposed into a number of indicators. Based on this a hierarchy model is established, and then, according to the structure judgment matrix model, levels are sorted. Finally, determine the weight of each indicator corresponding coefficients were always sort hierarchy [3,5].And the calculation process is as follows: 


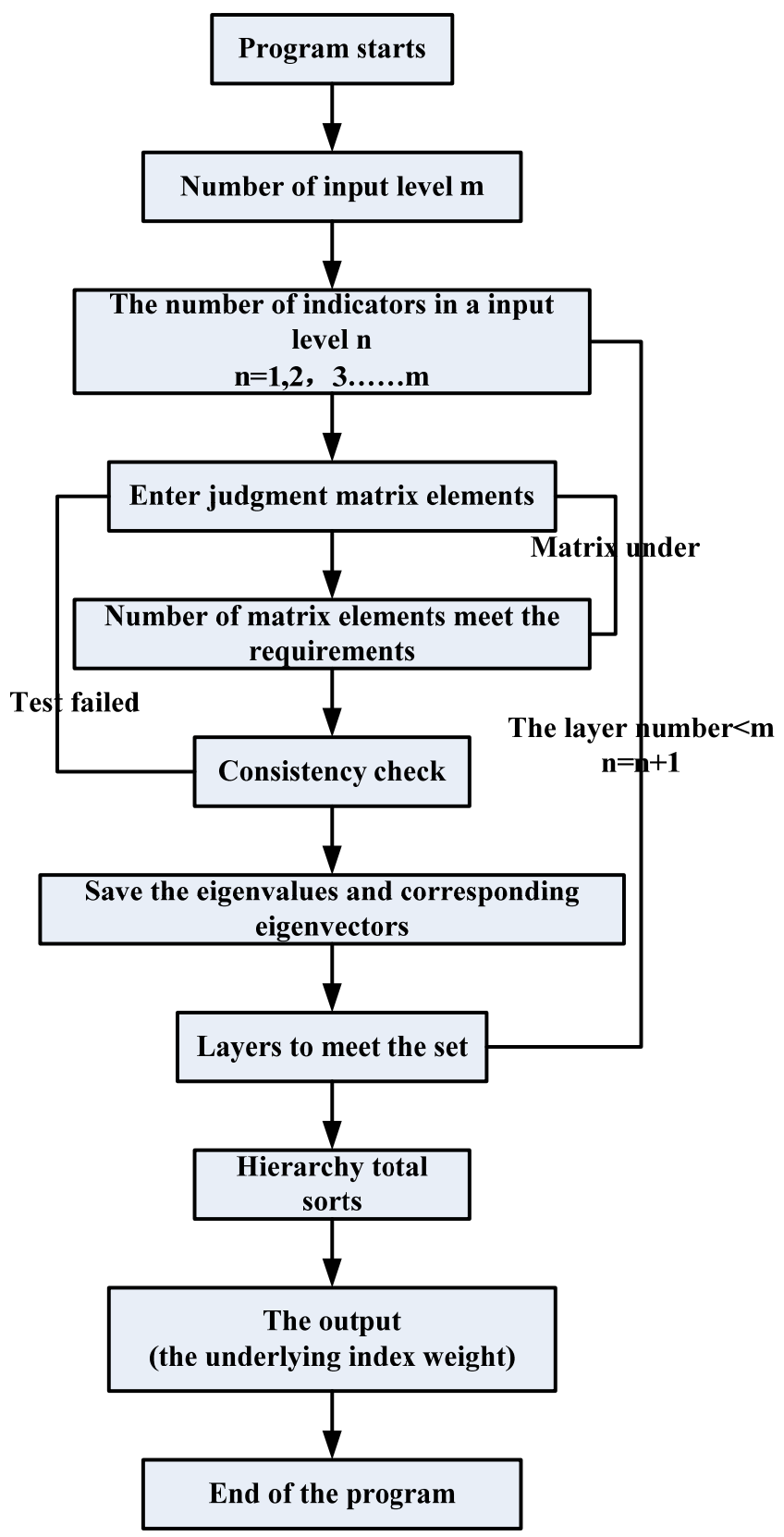

Fig.1 the calculation process of AHP

\subsection{Construct hierarchical model}

Conducting analysis of Analytic Hierarchy Process (AHP), the most important step is to establish a hierarchical model of indicators, according to the structure of the model after the judgment matrix. The matrix only judged by the consistency test, analysis and calculation can be carried out. Among them, the structural model can be designed into three levels, the highest level for the target level, decision-making purposes and to solve the problem, the middle layer of the factors to be considered in the decision-making. Decision-making is the norm, and the lowest level of decision-making is an alternative program. Generally speaking, there is no lower limit of the number of indicators for each criterion index layer, but in this paper the design of the program can only be assumed that the index has the same number of lower-level indicators to complete AHP, and the caseselected the article text also satisfy this assumption.

\subsection{Establish judgment matrix}

The judgment matrix is a layer of all the factors for a particular factor to determine the relative importance of the assignment matrix elements, often using nine scale method (ie, digital 1-9 and reciprocal representation between indicators relative importance), specific scaling method shown in Table 1. 
Table 1 Professor T.L.Saaty1-9 Scale method

\begin{tabular}{|c|c|c|}
\hline scale & define & meaning \\
\hline 1 & As important & $\begin{array}{c}\text { Two elements of certain attributes are } \\
\text { equally important }\end{array}$ \\
\hline 3 & A little important & $\begin{array}{l}\text { Two elements of certain properties, one element is more } \\
\text { important than a elements slightly }\end{array}$ \\
\hline 5 & Obvious important & $\begin{array}{l}\text { Two elements of certain properties, one element is more } \\
\text { important than a elements obviously }\end{array}$ \\
\hline 7 & Highly important & $\begin{array}{l}\text { Two elements of certain properties, one element is more } \\
\text { important than a elements strongly }\end{array}$ \\
\hline 9 & $\begin{array}{l}\text { Extremely } \\
\text { important }\end{array}$ & $\begin{array}{l}\text { Two elements of certain properties, one element is more } \\
\text { important than a elements extremely }\end{array}$ \\
\hline $2,4,6,8$ & Critical Mean value & Intervenienttwo adjacent scales \\
\hline
\end{tabular}

\subsection{Check judgment matrix consistency}

The complexity of multi-stage judgment often makes the possibility of some value judgment matrix inconsistent, and then each judgment matrix does not guarantee full harmonization. When the judgment matrix cannot guarantee full consistency of judgment matrix corresponding characteristic, root will also change, so they can be used to determine the characteristic roots of the matrix changes to test to determine the degree of consistency. In AHP, judgment matrix largest eigenvalues $\lambda$ max is the index recorded judgment matrix consistency test.

ThegreaterCI valuesare, the worseconsistency of judgment matrixesare. When the order is greater than 2, judgment matrix consistency index CI with the same order of average random consistency index RI is called random consistency ratio, andCR is calculated as follows:

When $\mathrm{CR}<0.1$, the judgment matrix can be considered satisfactory consistency. However, due to the presence of subjective factors in the decision process for the degree of importance of each index mutual size, cannot pass judgment matrix consistency test, and the need for the degree of importance of each index mutual re-assignment until it pass matrix consistent test. Its biggest feature is the value of the corresponding feature vector with respect to the index level indicators in order of importance.

\subsection{Sort level}

After sorting through a single draw level on the relative importance of each indicator vector sort of level indicators, hierarchical structure to perform matrix calculation by the bottom-upcan be obtained on the relative importance of each of the underlying index at the highest level weights, which can prioritize each of the underlying index to sort and identify indicators focus special attention.

\section{Experiment and Analysis}

Private Finance Initiative (PFI) is a financing model, aimed at mobilizing private capital for better construction, and promote economic development. In developing the plan formulation, risk control is very important. There are many kinds of risk factors, which is not conducive to a comprehensive control and assurance; but there is a certain link between them, you can select from important factors, in order to facilitate the development of the plan. Principal component analysis (PCA) is a major factor algorithm, and it is widely used in many field [1,3]. Therefore this method will be used in the risk assessment, and to provide a reference for the development direction of small town.

Construct establishment projects under the PFI model many participants, and the relationship structure diagram is presented in fig.2. And, in order to facilitate research, four participants are selected: government (a1), the project company (a2), the lending bank (a3), Guarantee Corporation (a4). To quantify the size of the risk evaluation, 8 index of evaluation factors including the political risks (y1), financial risks (y2), credit risk (y3), operational risks (y4), completion risk (y5), market risk (y6), environmental risks (y7) and force majeure risk (y8), are scored by experts, and are shown in Table 2.The comparative scale values of factors importance are shown in Table 3.

Finally, The consistency checking results are presented in table.4, and the final risk estimation values of sectors are presented in fig.3. As shown in Table.4, all the original data pass the consistency 
checking. And judged from fig.3, it can be known that the project company suffer from the highest risk.

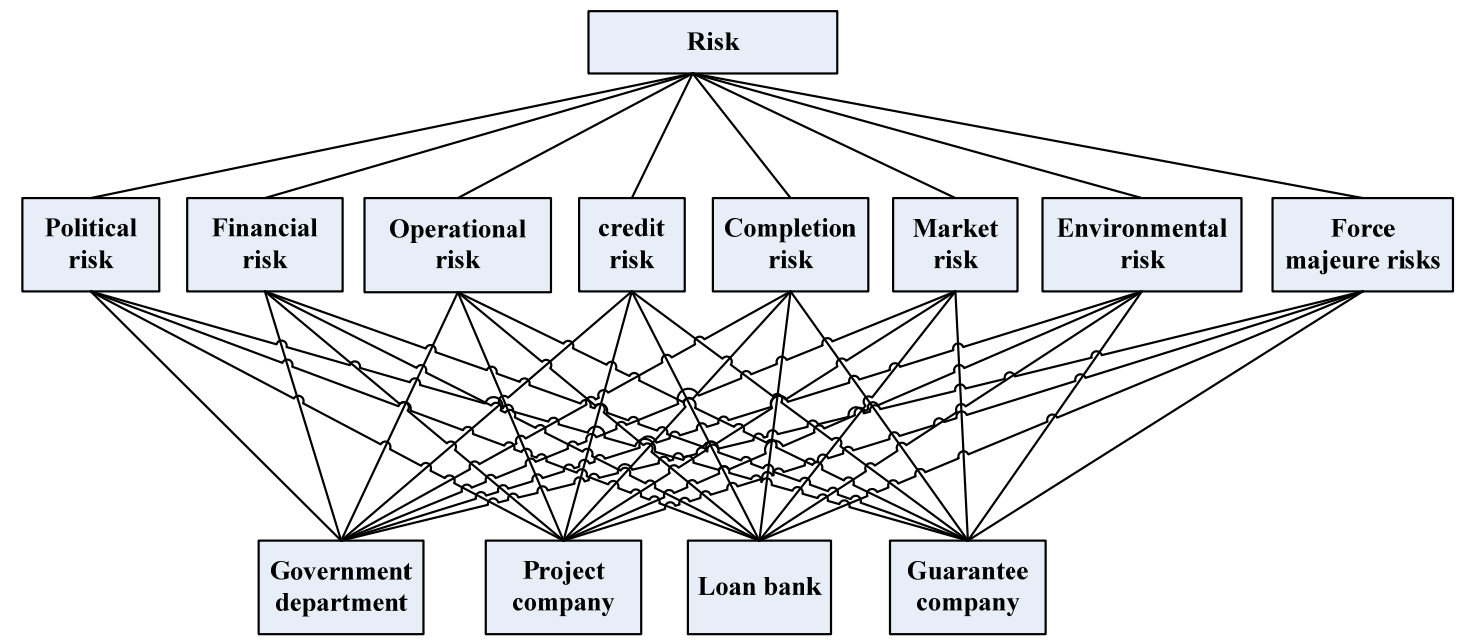

Fig.2 The relationship structure diagram of the model

Table 2 The original data

\begin{tabular}{ccccccccc}
\hline Departments & Political & Financial & Credit & Operational & Completion & Market & $\begin{array}{l}\text { Environmental } \\
\text { protection }\end{array}$ & $\begin{array}{l}\text { Force } \\
\text { majeure }\end{array}$ \\
\hline & $\mathrm{y} 1$ & $\mathrm{y} 2$ & $\mathrm{y} 3$ & $\mathrm{y} 4$ & $\mathrm{y} 5$ & $\mathrm{y} 6$ & $\mathrm{y} 7$ & $\mathrm{y} 8$ \\
government & 7.6 & 6.1 & 5.0 & 4.8 & 6.1 & 6.4 & 3.0 & 6.5 \\
project company & 4.8 & 8.8 & 5.0 & 8.1 & 9.5 & 8.3 & 6.0 & 6.5 \\
lending bank & 2.1 & 3.2 & 5.3 & 2.2 & 3.5 & 2.5 & 1.5 & 1.5 \\
bonding company & 2.3 & 2.5 & 3.0 & 2.0 & 2.5 & 2.1 & 2.0 & 6.5 \\
\hline
\end{tabular}

Table 3 The comparative scale values of factors importance

\begin{tabular}{ccccccccc}
\hline $\mathrm{y}_{\mathrm{j}} / \mathrm{y}_{7}$ & $\mathrm{y}_{1} / \mathrm{y}_{7}$ & $\mathrm{y}_{2} / \mathrm{y}_{7}$ & $\mathrm{y}_{3} / \mathrm{y}_{7}$ & $\mathrm{y}_{4} / \mathrm{y}_{7}$ & $\mathrm{y}_{5} / \mathrm{y}_{7}$ & $\mathrm{y}_{6} / \mathrm{y}_{7}$ & $\mathrm{y}_{7} / \mathrm{y}_{7}$ & $\mathrm{y}_{8} / \mathrm{y}_{7}$ \\
$U_{j 7}$ & 3 & 4 & 5 & 8 & 7 & 8 & 1 & 1 \\
\hline
\end{tabular}

Table 4 The consistency checking result

\begin{tabular}{cccccccccc}
\hline Data type & Weight & Policy & Finance & Credit & Operation & Completion & Market & Environment & Majeure \\
$\lambda_{\max }$ & 8 & 4 & 4 & 4 & 4 & 4 & 4 & 4 & 4 \\
CR & 0 & 0 & 0 & 0 & 0 & 0 & 0 & 0 & 0 \\
$\begin{array}{c}\text { Checking } \\
\text { result }\end{array}$ & pass & pass & pass & pass & pass & pass & pass & pass & pass \\
\hline
\end{tabular}

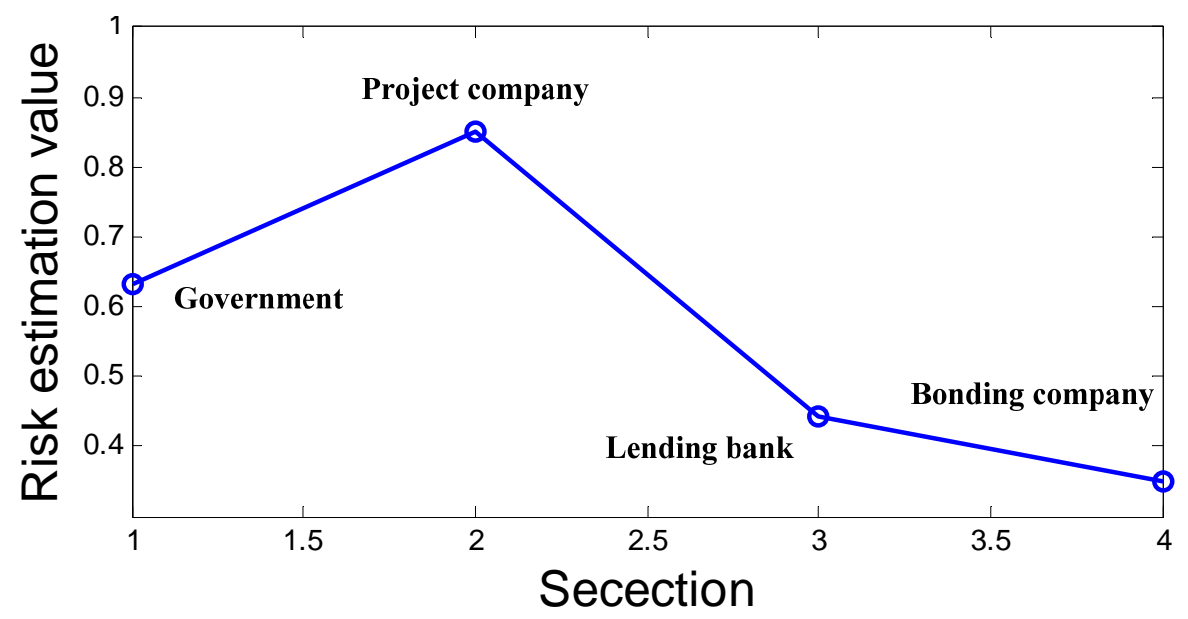

Fig.3 The risk estimation values of sectors 


\section{Conclusion}

In order to extract vital factors for the establishment of small town, AHP is introduced there. At first, the brief introduction of PFI is illustration. Secondly, the theory and the calculation process of AHP are presented. And then the risk estimation of four sections are calculated. And the principal components are extract from all 8 factors. And the result may be worth considering as making establishment plan.

\section{Acknowledgments:}

This work is supported by the Project Foundation of Shaanxi Province Education Department (NO. 2013JK0169).

\section{References}

[1] Akintoye A, Hardcastle C, Beck M, et al. Achieving best value in private finance initiative project procurement [J]. Construction Management and Economics, 2003, 21(5): 461-470.

[2]Allen G. The private finance initiative (PFI) [M]. House of Commons library, 2003.

[3]Harker P T. Analytic hierarchy process [M]. Pergamon, 2003.

[4]Saaty T L. Decision making with the analytic hierarchy process [J]. International journal of services sciences, 2008, 1(1): 83-98.

[5]Saaty T L. Fundamentals of decision making and priority theory with the analytic hierarchy process [M]. Rws Publications, 2000. 